\title{
El reconocimiento legal de la economía social en Europa. Alcance y consecuencias
}

The legal recognition of the social economy in Europe. Scope and consequences

O reconhecimento legal da economia social na Europa. Âmbito e conseqüências

\section{Isabel Gemma Fajardo García*}

\author{
Recibido: 14 de julio de 2018 \\ Aceptado: 11 de septiembre de 2018 \\ Publicado: 5 de abril de 2019 \\ Cómo citar este artículo: \\ Fajardo-García, I.G. (2019). El reconocimiento legal de la economía social \\ en Europa. Alcance y consecuencias. \\ Cooperativismo \& Desarrollo, 27(1), 1-31. \\ DOI: https://doi.org/10.16925/2382-4220.2019.01.06
}

Artículo de investigación.

* Universidad de Valencia. Valencia. España.

ORCID: https://orcid.org/0000-0003-3398-706X

Correo electrónico: fajardo@uv.es 


\section{Sumario}

1. Introducción. 2. Breve referencia al origen y evolución del concepto de economía social en Europa desde la literatura científica y desde las instituciones europeas hasta el 2009. 3. La identificación de la economía social a nivel europeo y sus consecuencias a partir de la Resolución del Parlamento Europeo sobre la Economía Social de 2009. 4. La economía solidaria para las instituciones europeas. 5. La regulación legal de la economía social en Europa. De la Ley española de 2011 a la Ley griega de 2016. 5.1. Justificación de la Ley. 5.2. Definición de economía social (y solidaria). Fines y principios. 5.3. Identificación de las llamadas "entidades de la economía social". 5.4. Acreditación de la condición de entidad de la economía social. 6. Conclusiones. Referencias.

\section{Resumen}

El concepto de economía social se encuentra en la doctrina y en las políticas públicas en la Unión Europea y en sus Estados miembros desde la década de los ochenta del siglo xx. En el 2009, el Parlamento Europeo instó a los Estados a regular la economía social, a fin de visibilizarla y estar en capacidad de elaborar y aplicarle políticas de fomento tanto desde la Unión Europea como desde los Estados. Nos hemos planteado hasta qué punto ha tenido respuesta esta recomendación del Parlamento Europeo y hemos analizado las legislaciones europeas dictadas en torno a la economía social y solidaria, buscando destacar sus rasgos de identidad como, por ejemplo, el concepto, los fines y los principios, así como los modelos de empresa propuesta y el sistema de acreditación de su condición de empresa de la economía social. A partir del análisis de las leyes aprobadas a partir del 2009, se llega a la conclusión de que, si bien se ha dado un reconocimiento legal de la economía social, este no ha sido muy extendido y, además, los avances en favor de su promoción no han sido significativos. Por una parte, la pluralidad de conceptos que se han generado en torno a la economía social (economía solidaria, economía colaborativa, empresa social, emprendimiento social) están creando confusión sobre su concepto y ámbito. Por otra, porque las empresas clásicas de la economía social (cooperativas, mutuas, asociaciones y fundaciones) son aún objeto de discriminación en la regulación relativa a los empresarios (sociedades, contabilidad, fiscalidad, competencia, etc.) y a las actividades empresariales, razón que en su momento justificó la unión de las empresas de la economía social para reivindicar su derecho a desarrollarse en igualdad de condiciones frente a las empresas de capital.

Palabras clave: economía social, economía solidaria, empresa social, Europa, legislación.

\section{Summary}

The concept of the social economy is found in the doctrine and public policies of the European Union and its member states since the eighties of the twentieth century. In 2009, the European Parliament urged the States to regulate the social economy, in order to make it visible and be able to draw up and apply promotion policies from both the European Union and the States. We have considered to what extent this recommendation of the European Parliament has been answered and we have analyzed the European legislations dictated around the social and solidarity economy, seeking to highlight its identity features such as, for example, the concept, the aims and the principles, as well as the models of the proposed company and the accreditation system of its status as a social economy company. From the analysis of the laws passed after 2009, it is concluded that, although there has been a legal recognition of the social economy, this has not been very widespread and, in addition, the advances in favor of its promotion have not been significant. On the one hand, the plurality of concepts that have been generated around the social economy (solidarity economy, collaborative economy, social enterprise, social entrepreneurship) are creating confusion about its concept and scope. On the other hand, because the classic companies of the social economy (cooperatives, mutual societies, associations and foundations) are still subject to discrimination in the regulation concerning entrepreneurs 
Key words: social economy, solidarity economy, social enterprise, Europe, legislation.

\section{Resumo}

O conceito de economia social encontra-se na doutrina e políticas públicas da União Européia e seus estados membros desde os anos oitenta do século XX. Em 2009, o Parlamento Europeu instou os Estados a regulamentar a economia social, a fim de torná-la visível e capaz de elaborar e aplicar políticas de promoção tanto da União Europeia como dos Estados. Nós estabelecemos o quanto foi respondida esta recomendação do Parlamento Europeu e analisaram a legislação europeia promulgada em torno da economia social e solidária, buscando destacar sua identidade características como, por exemplo, o conceito, objectivos e princípios, bem como os modelos da empresa proposta e o sistema de acreditação do seu estatuto de empresa de economia social. A partir da análise das leis aprovadas após 2009, conclui-se que, embora tenha havido um reconhecimento legal da economia social, isso não tem sido muito difundido e, além disso, os avanços a favor de sua promoção não tem sido significativa. Por um lado, a pluralidade de conceitos que foram gerados em torno da economia social (economia solidária, economia colaborativa, empreendimento social, empreendedorismo social) está criando confusão sobre seu conceito e escopo. Por outro lado, porque as empresas clássicas da economia social (cooperativas, sociedades mútuas, associações e fundações) continuam sujeitas a discriminação no regulamento relativo aos empresários

Palavras - chave: economia social, economia solidária, empresa social, Europa, legislação.

\section{Introducción}

En Europa se ha forjado de manera progresiva el concepto de economía social desde la década de los setenta del siglo pasado, tanto por la doctrina como por las instituciones públicas y las organizaciones identificadas con la economía social. El concepto de economía social ha evolucionado según las particularidades de cada Estado miembro de la Unión Europea, pero a la vez se ha buscado consensuar una identidad común que favorezca su visibilidad y permita promover políticas para su fomento a nivel europeo. Estos objetivos quedaron plasmados en la Resolución del Parlamento Europeo del 2009 sobre la economía social. Era de esperar que ese esfuerzo por alcanzar una imagen unificada de la economía social, se viera reflejado en la posterior regulación llevada a cabo por los Estados miembros; sin embargo, la realidad nos muestra que este es todavía un objetivo a conseguir. Nuestro propósito en este trabajo es poner de manifiesto las diversas orientaciones que la economía social ha seguido en Europa a partir del momento en que los Estados han comenzado a identificarla y regularla. Para esto, se analizan las diversas leyes aprobadas y, en particular, las normas que definen la economía social y describen las entidades que la integran, así como los requisitos que deben cumplir para su acreditación. Se concluye con una valoración crítica del marco legal de la economía social en Europa. 


\section{Breve referencia al origen y la evolución del concepto de economía social en Europa desde la literatura científica y desde las instituciones europeas hasta el 2009}

El concepto de economía social, tal y como hoy lo conocemos, lo comienzan a utilizar en Francia las organizaciones representativas de las cooperativas, de las mutuas y las asociaciones que constituyeron un comité nacional (el CNLAMCA), y aprobaron el 22 de mayo de 1982 un manifiesto bajo el título de "Carta de la economía social". Con dicha carta se identifican como empresas que comparten fines y características, y reivindican su derecho al desarrollo en igualdad de oportunidades con otros modelos de empresa. Todas ellas tienen en común su finalidad de servicio al ser humano, así características tales como su gestión democrática e independiente de los poderes públicos, la igualdad de derechos y deberes de los socios, la constante formación e información a estos, la distribución de los excedentes para el crecimiento de la empresa y la mejora de los servicios prestados a sus socios, así como la promoción de la investigación y del desarrollo sostenible de la sociedad.

Las empresas de la economía social nacen como reacción frente a los abusos del liberalismo industrial durante el siglo XIX y se basan en el asociacionismo, la cooperación y solidaridad para hacer frente a las necesidades esenciales de las personas. Estas formas de empresa fueron reconocidas en las legislaciones europeas a lo largo de los siglos XIX y XX, pero no se han tenido en cuenta tradicionalmente a la hora de regular los derechos y las obligaciones de los empresarios, e incluso se le ha negado esta consideración. Las legislaciones fiscal, contable, concursal o de la competencia, por poner algunos ejemplos, se elaboran con base en el modelo de la empresa de capital, pero luego se aplican a todo tipo de empresas sin tener en cuenta sus diversos fines y estatutos. Lo mismo ocurre en relación con la normativa que regula la actividad empresarial y los diversos sectores económicos: son normas dictadas para su aplicación a empresas de capital animadas por fines lucrativos y en las que no se tiene en cuenta la participación en dicho sector de otros modelos de empresa. Esto cuando no se les excluye de forma directa de participar en dicho sector (sectores de la energía o de las telecomunicaciones), o se les conmina a abandonar su estatuto jurídico para que puedan seguir operando en el mismo (sector del crédito y de los seguros). 
El concepto de economía social pronto se expande a otros países como Bélgica ${ }^{1}$ o España, ${ }^{2}$ y lo comienzan a utilizar las instituciones europeas.

Desde un punto de vista científico, el concepto de economía social lo manejaba en el siglo XIX la doctrina ${ }^{3}$, pero en el sentido con el que hoy lo conocemos comienza a estudiarse y difundirse a partir de 1980, lo que se interpreta como un redescubrimiento del concepto. Si bien en la literatura científica podemos encontrar tempranas obras de referencia en torno al concepto de economía social y sus componentes, ${ }^{4}$ especial interés tiene el concepto de empresa de economía social elaborado para la Comisión Europea por el Centro Internacional de Investigación e Información sobre la Economía Pública, Social y Cooperativa (Ciriec), en el propósito de estar en capacidad de cuantificar su relevancia en la economía nacional o europea.

Esta organización define las empresas de la economía social como un,

Conjunto de empresas privadas organizadas formalmente, con autonomía de decisión y libertad de adhesión, creadas para satisfacer las necesidades de sus socios a través del mercado, produciendo bienes y servicios, asegurando o financiando y en las que la eventual distribución entre los socios de beneficios o excedentes así como la toma de decisiones, no están ligados directamente con el capital o cotizaciones aportadas por cada socio, correspondiendo un voto a cada uno de ellos. La economía social también agrupa a aquellas entidades privadas organizadas formalmente con autonomía de decisión y libertad de adhesión que producen servicios de no mercado a favor de las familias, cuyos excedentes, si los hubiera, no pueden ser apropiados por los agentes económicos que las crean, controlan o financian (Barea y Monzón, 2007, p. 36).

1 En 1988 se constituye en Bélgica el Consejo de la Economía Social con participación de representantes del Gobierno y de las organizaciones representativas de las entidades de la economía social.

2 En 1990 se crea en España el Instituto Nacional de Fomento de la Economía Social, el cual sucede a la antigua Dirección General de Cooperativas y Sociedades Laborales del Ministerio de Trabajo, y en 1992 se crea Cepes (Confederación Empresarial Española de la Economía Social).

3 Algunas obras citadas por Jeantet y Verdier (1982, p. 25) son: Traité d'économie sociale, de Le Play (1830); Manuel de l'économie social de Benoît Malon (1883), o Traité de l'économie sociale de Auguste Ott (1892).

4 Entre otras, pueden citarse: L'économie sociale, de Thierry Jeantet y Roger Verdier (1982); Essai sur une politique de l'économie sociale, de Jacques Moreau (1982); L'économie sociale, Qué sais-je?, de André Neurisse (1983), o Concepts et champs de l'économie sociale, de Claude Vienney (1983). 
El interés de las instituciones europeas por la economía social se manifiesta, principalmente, a partir de la creación, en 1989, de un servicio dedicado a la economía social en el marco de la XXIII Dirección General de la Comisión Europea, lo que impulsó la aprobación de la comunicación de la Comisión al Consejo "Las empresas de la Economía Social y la realización del mercado europeo sin fronteras", la elaboración de proyectos de estatutos europeos para las cooperativas, asociaciones y mutualidades, ${ }^{5}$ o la creación, en 1998, de un órgano de enlace permanente con el sector de la economía social: el Comité Consultivo de las Cooperativas, Mutualidades, Asociaciones y Fundaciones (CEP-CMAF), lo cual evidencia la ampliación del ámbito de la economía social a las fundaciones.

El CEP-CMAF aprobó en el 2002 la "Carta de la Economía Social Europea", en la cual reconoce que las organizaciones de la economía social son actores económicos y sociales presentes en todos los sectores de la economía, y se caracterizan por su finalidad y su forma diferente de emprender. Según la carta, la economía social comprende las cooperativas, las mutualidades, las asociaciones y las fundaciones, empresas que se distinguen de las de capital por una serie de características comunes o valores fundamentales denominados "Principios de la economía social". ${ }^{6}$ En el 2008, el CEP-CMAF se transforma en la actual organización representativa de las entidades de la economía social europea denominada Social Economy Europe (SEE), la cual continúa en la defensa de sus principios de la economía social y ha ampliado su ámbito a otros nuevos modelos de empresa, como, por ejemplo, las "empresas sociales".?

Otro hito importante en la configuración de la economía social tiene lugar en el 2000 con la aprobación, por parte del Comité Económico y Social Europeo (CESE),

5 De todos esos proyectos solo llegó a buen fin, años después, el relativo a la cooperativa, con la aprobación, el 22 de julio del 2003, del Reglamento (CE) n. ${ }^{\circ}$ 1435/2003 del Consejo, relativo al Estatuto de la Sociedad Cooperativa Europea (SCE). Esta norma no ha gozado de aceptación en el sector, tal como se puso de manifiesto en el "Informe de la Comisión de 23 de febrero de 2012" sobre la aplicación de dicho Reglamento (сом (2012) 72 final). Entre los motivos señalados se encuentra la escasa identificación del estatuto con los principios cooperativos. A falta de una armonización previa de la legislación cooperativa en los países europeos, al tratar de consensuar un régimen común para la sociedad cooperativa europea se adoptó el mínimo común denominador y constantes remisiones a la legislación aplicable a la sociedad anónima europea.

6 Estos principios son: 1. Prioridad de la persona y del objeto social sobre el capital; 2. Adhesión voluntaria y abierta; 3 . Control democrático por sus miembros (a excepción de las fundaciones); 4. Conjunción de los intereses de los miembros y del interés general; 5 . Defensa y aplicación de los principios de solidaridad y responsabilidad; 6 . Autonomía de la gestión e independencia respecto a los poderes públicos; 7 . Destino de la mayoría de sus excedentes a la consecución de objetivos a favor del desarrollo sostenible, la mejora de los servicios a los miembros y el interés general.

7 Véase http://www.socialeconomy.eu.org/who-see 
del dictamen sobre "Economía social y mercado único", ${ }^{8}$ en el cual se cuestiona el concepto de economía social tal y como se había descrito hasta el momento, esto es, como un conjunto de formas organizativas y jurídicas (cooperativas, mutualidades, asociaciones y fundaciones). El CESE critica que la forma jurídica sea el elemento determinante para definir la economía social, a pesar de reconocer que la mayor parte de las empresas de la economía social estén organizadas con algunas de esas formas, lo cual es así porque - según dice- por una parte, no todas las organizaciones incluidas en esas familias se consideran parte de la economía social, otras organizaciones que se identifican con los principios de la economía social no adoptan esas formas jurídicas, y, finalmente, porque esas mismas formas jurídicas carecen de una naturaleza y regulación homogénea en los diversos Estados miembros. Cabría añadir a esta última razón que, precisamente, carecen de una regulación homogénea porque, a diferencia de la sociedad anónima cuya regulación ha sido objeto de armonización en los diversos países europeos durante años, no se ha hecho el menor esfuerzo por aproximar mínimamente la concepción ni la regulación de las empresas de la economía social en Europa.

El CESE concibe la economía social como una conjunción de "economía" y "social", y por esto la describe como una "actividad económica" que, además, es social, ya que persigue la ayuda mutua de sus miembros o un interés de carácter general. La economía social es, por tanto, para el CESE un tipo de empresa - diferente de la empresa privada clásica y del sector público- que se caracteriza porque centra su interés en satisfacer necesidades concretas de interés público de las personas, bien sean estas sus miembros, sus usuarios o bien la sociedad en general. Además de cumplir con este objetivo, las entidades de la economía social deben estar abiertas a todo aquel que cumpla los requisitos y acepte las condiciones, deben estar controladas democráticamente, su gestión debe ser independiente y son organizaciones not-for-profit, lo que no excusa que deben esforzarse por ser económicamente eficientes. ${ }^{9}$

8 Véase el Diario Oficial de las Comunidades Europeas c 117, del 26 de abril del 2000.

9 Curiosamente, el carácter no lucrativo de las entidades de economía social clásicas que el CESE reivindica va a perder relevancia con el tiempo a la hora de definir la economía social, y va a empezar a ser reivindicado por las sociedades mercantiles que se reclaman como pertenecientes a la economía social y solidaria. La ausencia de ánimo de lucro está presente tanto en las entidades de base mutualista en cuanto cooperativas y mutualidades como en las entidades con fines de interés general en su calidad de asociaciones y fundaciones, pero con distinto significado. En las primeras falta el ánimo de lucro objetivo, porque la actividad económica no se desarrolla con el fin de obtener el máximo beneficio, sino para mejorar los precios pagados o cobrados a sus miembros, bien sean estos trabajadores, proveedores, usuarios o bien consumidores. Por tanto, puede existir una relación inversa, un mejor cumplimiento del objeto social de la entidad puede conllevar un menor beneficio, y a la inversa. En las segundas, puede faltar el ánimo de lucro objetivo también, pero lo más frecuente es que estas entidades sí busquen obtener beneficios con su actividad económica, con el fin de destinarlos a sus objetivos sociales. 


\section{La identificación de la economía social a nivel europeo y sus consecuencias a partir de la Resolución del Parlamento Europeo sobre la Economía Social del 2009}

El Parlamento europeo aprobó el 19 de febrero del 2009 una resolución titulada "Economía Social" (2008/2250 (INI)), en la cual reconoce que la economía social es un modelo de empresa que se ha desarrollado bajo formas jurídicas tales como cooperativas, mutualidades, asociaciones, fundaciones, empresas sociales y otras formas existentes en cada Estado miembro. También reconoce que el concepto de economía engloba otros conceptos utilizados por los Estados como, por ejemplo, "economía solidaria" o "tercer sector", los cuales, aunque no se definan como economía social, comparten sus mismos valores y características, los que identifica con los "Principios de la economía social" aprobados por las entidades de la economía social.

En esta resolución, el Parlamento Europeo subraya el papel que desempeña la economía social en Europa al contribuir a la creación de empleo de calidad, reforzar la cohesión social económica y territorial, generar capital social, fomentar la ciudadanía activa y solidaria, fomentar el desarrollo sostenible, y la innovación social, medioambiental y tecnológica. Por tanto, aboga ante la Comisión Europea y los Estados miembros para que se reconozca y fomente la economía social. En particular, solicita a la Comisión que defina el concepto de economía social como un "enfoque diferente de empresa" cuyo motor principal no es la rentabilidad financiera, sino los beneficios para toda la sociedad, de modo que las particularidades de la economía social se tomen debidamente en cuenta en la elaboración de los marcos jurídicos (considerando n. ${ }^{\circ}$ ).

El Parlamento Europeo también reclama el reconocimiento jurídico de estatutos para las asociaciones, las fundaciones y las mutualidades de ámbito transfronterizo, un reconocimiento estadístico de las empresas de economía social y la elaboración de cuentas satélites nacionales, y un reconocimiento como interlocutor social, de forma que los representantes de la economía social se reconozcan en el diálogo social, sectorial e intersectorial de la Unión (considerando n. ${ }^{\circ}$ 17).

Por último, el Parlamento europeo pide a la Comisión y a los Estados miembros que integren la dimensión "economía social" en la elaboración de las políticas

En este caso la ausencia de lucro subjetivo deriva de la no distribución de los beneficios obtenidos entre sus miembros. Puede decirse, por tanto, que desde un punto visto jurídico la ausencia de ánimo de lucro es y debería seguir siendo una característica estructural de las entidades que integran la economía social. 
comunitarias y nacionales; asimismo, a la primera que tenga en cuenta la realidad de la economía social al revisar la política de ayudas estatales, puesto que las pequeñas empresas y las organizaciones que operan a escala local tienen grandes dificultades para acceder a la financiación. Pide también a la Comisión que no obstaculice las normativas nacionales en materia de sociedades o en materia fiscal, como, por ejemplo, las destinadas a las cooperativas en los sectores bancario y de la gran distribución, las cuales operan sobre la base de los principios de la mutualidad, de la democracia societaria, de la transmisión del patrimonio entre generaciones, de la indivisibilidad de las reservas, de la solidaridad, de la ética del trabajo y de la empresa.

Poco después, en el 2011, la Comisión Europea aprueba la "Iniciativa en favor del emprendimiento social", subtitulada "Construir un ecosistema para promover las empresas sociales en el centro de la economía y la innovación sociales". ${ }^{10}$ Esta iniciativa define la "empresa social" y adopta un plan de acción con el fin de apoyar el "emprendimiento social en Europa".

La Comisión parte de reconocer, tras una consulta pública, que las empresas sociales y la economía social, en general, aportan respuestas innovadoras a los actuales desafíos económicos, sociales y, en ocasiones, medioambientales, mediante el desarrollo de puestos de trabajo sostenibles -y difíciles de deslocalizar-, la integración social o la mejora de los servicios sociales locales.

La Comisión Europea concibe la empresa social en términos de un agente de la economía social, y la describe como una empresa cuyo principal objetivo es tener una "incidencia social" - más que generar beneficios para sus propietarios o sus socios-, la cual funciona en el mercado al proporcionar bienes y servicios de manera empresarial e innovadora, y utiliza sus excedentes, principalmente, para fines sociales. Las empresas sociales pueden ser de dos clases: (a) empresas que prestan servicios sociales o suministran bienes y servicios destinados a un público vulnerable; o (b) empresas cuyo modo de producción de los bienes o servicios persigue un objetivo de tipo social (integración social y profesional mediante el acceso a trabajo de personas desfavorecidas).

La empresa social no se concibe como una forma jurídica concreta, sino más bien como una calificación jurídica que se otorga a las empresas que reúnen los requisitos exigidos por la legislación que las regula. A diferencia de la cooperativa, la asociación, la fundación o la mutualidad, la empresa social tiene escaso

10 omunicación de la Comisión al Parlamento Europeo, al Consejo, al Comité Económico y Social Europeo y al Comité de las Regiones: "Iniciativa en favor del emprendimiento social. Construir un ecosistema para promover las empresas sociales en el centro de la economía y la innovación sociales" (com (2011) 682 final). 
reconocimiento legal en los Estados miembros de la Unión Europea, ${ }_{11}^{11}$ aunque es cierto que cada vez más Estados regulan nuevos modelos de empresa que pueden considerarse empresas sociales, bien sean empresas de inserción social o bien de iniciativa social. ${ }^{12}$

El Plan de acción para apoyar el emprendimiento social ${ }^{13}$ en Europa que concibe la Comisión europea consta de una serie objetivos y medidas a aplicar, con el fin de:

- Mejorar el acceso a la financiación de las empresas sociales. Así se les reconoce prioridad en la aplicación del Fondo Social Europeo y el Fondo de Desarrollo Regional (Feder), y se regulan, por vez primera en su beneficio, los Fondos de emprendimiento social europeo. ${ }^{14}$

- Mejorar el entorno jurídico:

- Con la creación de un estatuto europeo para las empresas sociales. ${ }^{15}$

- Al reformar la normativa sobre contratación pública con el fin de dar mayor valor al elemento de la "calidad" en la adjudicación de los contratos, sobre todo en el caso de los servicios sociales y sanitarios, y estudiar cómo podrían tenerse en cuenta las condiciones de trabajo de las personas que participan en la producción de los bienes y servicios objeto del contrato. ${ }^{16}$

11 Este es el caso de Finlandia (Ley 1351/2003, del 30 de diciembre de empresa social); Lituania (Ley ix-2251/2004, del 1 de junio de empresas sociales); Italia (Ley 118/2005, del 13 de junio de empresa social); Eslovenia (Ley 20/2011, del 25 de marzo de emprendimiento social); o Dinamarca (Ley 711/2014, del 25 de junio de registro de empresas sociales).

12 Este es el caso de Bélgica (Ley de Sociedades de Finalidad Social del 13 de abril de 1995); Reino Unido (Ley 1788/2005, del 30 de junio, de sociedades de interés comunitario); España (Ley de Empresas de Inserción 44/2007, del 13 de diciembre; Francia (Código de Trabajo, art. L 3332-17-1 sobre empresas solidarias y utilidad social); o Luxemburgo (Ley para la creación de Sociedades de Impacto Social, del 12 de diciembre del 2016).

13 La Comisión y, en general, las instituciones europeas, utilizan desde hace algún tiempo indistintamente como sinónimas las expresiones de "empresa social" y "emprendimiento social", a pesar de las diferencias que señala la doctrina. Véase sobre el particular Guridi y Pérez (2014), o Monzón y Chaves (2017).

14 Reglamento (ue) N. ${ }^{\circ}$ 346/2013 del Parlamento Europeo y del Consejo de 17 de abril de 2013 sobre los fondos de emprendimiento social europeos.

15 Existe en estos momentos una iniciativa legislativa del Parlamento Europeo para la aprobación del estatuto para las empresa social y solidaria (2016/2237(INI)) sobre la base del estudio realizado por Antonio Fici, "A European statute for social and solidarity-based enterprises", disponible en: http://www.europarl.europa.eu/RegData/etudes/STUD/2017/583123/IPOL_ STU(2017)583123_EN.pdf

16 Esta reforma se llevó a cabo con la aprobación de las siguientes normas: Directiva 2014/23/ UE, del Parlamento Europeo y del Consejo, del 26 de febrero del 2014, relativa a la adjudicación de contratos de concesión; Directiva 2014/24/UE, del Parlamento Europeo y del Consejo, del 26 de febrero del 2014, sobre contratación pública, y por la que se deroga la Directiva 2004/18/CE 
- Al reformar la normativa sobre ayudas de estado con el fin de simplificar la aplicación de dichas normas a los servicios sociales y a los servicios locales. Esta simplificación podría beneficiar también a las empresas sociales, en la medida en que estas prestan servicios sociales. ${ }^{17}$

- Mejorar la visibilidad del emprendimiento social:

- Al elaborar un mapa de las empresas sociales y sus ecosistemas en Europa. $^{18}$

- Al definir qué se entiende por empresa social.

Con este último fin, el Reglamento sobre el Programa de la Unión Europea para el Empleo y la Innovación Social N. ${ }^{0} 1296 / 2013^{19}$, define la empresa social como aquella empresa que, independientemente de su forma jurídica, presenta las siguientes características:

- En conformidad con su escritura de constitución, sus estatutos o cualquier otro documento constitutivo de la empresa, tiene por objetivo primordial la consecución de impactos sociales positivos y mensurables, en lugar de generar beneficios para sus propietarios, socios y accionistas. Asimismo:

- $\quad$ Ofrece servicios o bienes con un elevado retorno social.

- Emplea un método de producción de bienes o servicios que encarne su objetivo social.

y la Directiva 2014/25/ UE, del Parlamento Europeo y del Consejo, del 26 de febrero del 2014, relativa a la contratación por entidades que operan en los sectores del agua, la energía, los transportes y los servicios postales, y por la que se deroga la Directiva 2004/17/CE. Todas ellas se publicaron en el Diario Oficial de la Unión Europea del 28 de marzo del 2014, y su fecha límite de trasposición a los ordenamientos nacionales europeos era el 18 de abril del 2016.

17 El Reglamento (UE) N. ${ }^{0} 360 / 2012$ de la Comisión, del 25 de abril del 2012, relativo a la aplicación de los artículos 107 y 108 del "Tratado de funcionamiento de la Unión Europea" a las ayudas de mínimas concedidas a empresas que prestan servicios de interés económico general (servicios públicos), exime del deber de notificar a la Comisión Europea las ayudas concedidas a empresas que presten servicios de interés general si la ayuda concedida no excede de 500000 euros brutos durante un periodo de tres ejercicios fiscales (art. 2.2).

18 La Comisión Europea encargó la elaboración de un mapa de las empresas sociales y su eco-sistema en Europa (ICF Consulting, 2015), disponible en: http://ec.europa.eu/social/keyDocuments.jsp?advSearchKey=socentcntryrepts\&mode=advancedSubmit\&langl\&langld=en

19 Reglamento (UE) n. ${ }^{\circ}$ 1296/2013 del Parlamento Europeo y del Consejo, del 11 de diciembre del 2013, relativo a un Programa de la Unión Europea para el Empleo y la Innovación Social («EASI») y por el que se modifica la Decisión n. ${ }^{\circ} 283 / 2010 / u e$, por la que se establece un instrumento europeo de microfinanciación para el empleo y la inclusión social (Diario Oficial de la Unión Europea 1347 , del 20 de diciembre del 2013). 
- Utiliza sus beneficios, en primer lugar, para la consecución de su objetivo primordial, y ha implantado procedimientos y normas predefinidos que regulan cualquier reparto de beneficios a los accionistas y propietarios, con el fin de garantizar que dicho reparto no vaya en detrimento de su objetivo primordial.

- Se gestiona de forma empresarial, responsable y transparente, en especial mediante la participación de los empleados, los clientes o los interesados afectados por su actividad empresarial.

Más recientemente, el Consejo de la Unión Europea adoptó unas Conclusiones en su reunión del 7 de diciembre del 2015 bajo el título de "La promoción de la economía social como motor clave del desarrollo económico y social en Europa", en las que establece una serie de recomendaciones dirigidas a los Estados miembros, a la Comisión Europea, a las empresas de la economía social y a los emprendedores sociales. Este documento define la economía social como un conjunto de organizaciones basadas en la primacía de las personas sobre el capital, el cual incluye formas organizativas como, por ejemplo, cooperativas, mutuas, fundaciones y asociaciones, así como nuevas formas de empresas sociales. Por empresa social se deberá entender -recuerda el Consejo de la Unión Europea- aquella empresa que, independientemente de su forma jurídica, presente las características señaladas por el Reglamento 1296/2013 expuestas.

La empresa social se caracteriza, por tanto, por sus fines, por el tipo de actividad que desarrolla o por cómo la lleva a cabo; no obstante, puede adoptar cualquier forma jurídica siempre que le permita (legal o estatutariamente) relegar a un segundo plano la posible finalidad lucrativa de su actividad.

Las conclusiones del Consejo invitan a los Estados miembros y a la Comisión a establecer y aplicar estrategias y programas para reforzar la economía social, el emprendimiento social y la innovación social, y propone varías áreas: en el ámbito de la concienciación, del reconocimiento y de la educación; en el de la innovación social; asimismo, en el marco del entorno normativo y en el acceso a la financiación. Insta a la Comisión a que tenga en cuenta la economía social, la innovación social y las políticas de inversión social en la revisión de la estrategia Europea 2020, a que difunda las buenas prácticas de la economía social en Europa, y la apoye en aquellos países en que los índices de desempleo, especialmente de desempleo juvenil, femenino y de grupos vulnerables, son elevados. Por último, anima a las empresa de la economía social y a los emprendedores sociales a adoptar iniciativas que favorezcan el conocimiento de su sector y su impacto, la cooperación entre ellos y con los poderes públicos y otros 
interesados, así como a mejorar la cultura de empresa y la evaluación y la representación de las mujeres y la juventud en la gestión.

Como conclusión de los diversos documentos comentados cabe decir que las instituciones europeas identifican la economía social con actividades empresariales desarrolladas con ciertos fines y bajo determinados principios presentes en entidades que adoptan ciertas formas jurídicas o se identifican como empresas sociales, tal y como se definen en el Reglamento 1296/2013. Vimos también como el Parlamento, en su Resolución del 2009, reconoce que pueden utilizarse otros conceptos para hacer referencia a la misma realidad, como, por ejemplo, "economía solidaria" o "tercer sector", pues comparten los mismos valores y características. Sin embargo, las conclusiones del Consejo de la Unión Europea terminan por reconocer que el debate internacional sobre el desarrollo de la economía social y solidaria se hace cada vez más potente, y podría contribuir a conformar la agenda 2030 sobre desarrollo sostenible. La referencia del Consejo a esta nueva expresión "economía social y solidaria" sorprende, porque ni se define ni se hace ninguna otra alusión a ella, cuando hasta el momento el Parlamento había interpretado los conceptos de economía social y economía solidaria como equivalentes.

La expresión "economía social y solidaria" cobra interés en el ámbito jurídico europeo a partir de la aprobación en Francia, en el 2014, y más tarde en Grecia en el 2016, de sendas leyes relativas a la economía social y solidaria, como más tarde veremos, por lo cual resulta de interés profundizar en conocer qué sentido tiene esa expresión para las instituciones europeas.

\section{La economía solidaria para las instituciones europeas}

Las referencias a la economía solidaria por parte de las instituciones europeas no han sido hasta el momento muchas, pero aparte de las citadas, cabe destacar dos resoluciones del Parlamento Europeo de 1994 y el 2015.

En 1994, el Parlamento Europeo adoptó la Resolución sobre la economía alternativa y solidaria ${ }^{20}$ en la cual reconoció la existencia de diversas iniciativas de ciudadanos basadas en la innovación y la solidaridad que tenían por objeto hacer frente al desempleo y a la exclusión social mediante la creación de puestos de trabajo duraderos, y para las que solicitaba apoyo de la Unión Europea.

20 Véase Resolución sobre la Economía alternativa y solidaria, aprobada el 6 de mayo de 1994. Julio 25 de 1994. Diario Oficial 205. 
Estas iniciativas se caracterizan según la resolución porque:

- Las actividades económicas puestas en marcha para generar puestos de trabajo duraderos son útiles, social y ecológicamente, y se desarrollan en ámbitos muy diversos: vivienda, cultura, sanidad, condiciones de vida, turismo, artesanía, comercio, transporte, agricultura, protección del patrimonio natural, finanzas, energías renovables, comunicación, reciclaje de residuos, nuevas tecnologías, formación, etc.

- Utilizan instrumentos financieros de solidaridad para ayudar a la creación de actividades y empresas en ámbitos principalmente locales (barrio, ciudad, zona rural, región).

- En la promoción y el desarrollo de estas iniciativas suelen participar instituciones locales, colectividades territoriales, empresas tradiciones y redes de voluntarios.

Ante la constatación de estas iniciativas emergentes, el Parlamento europeo pedía a la Comisión que examinara la posibilidad de reactualizar un tercer sector económico que denomina "de la economía solidaria y voluntaria". El Parlamento europeo no desconoce la economía social en ese momento, es más, reconocía expresamente que la economía social en Europa era un sector creador de puestos de trabajo, y que las iniciativas que denomina de "economía alternativa y solidaria", desarrollan de forma positiva el sector de la economía social frente a los nuevos problemas surgidos con la crisis: la gran pobreza, las múltiples formas de exclusión, una crisis urbana y rural preocupante y el desmoronamiento del vínculo social. En definitiva, la economía alternativa y solidaria se identificaba como aquella parte de la economía social más centrada en el desarrollo local y en la creación de empleos estables para colectivos con difícil empleabilidad.

Esta resolución no tuvo posterior eco en las instituciones europeas ni en la legislación europea, pero más tarde, en el 2015, el Parlamento Europeo aprueba una resolución sobre emprendimiento social e innovación social en la lucha contra el desempleo ${ }^{21}$ en la que hace constantes referencias a la economía social y solidaria, y utiliza indistintamente los términos de economía social y economía social y solidaria

21 Véase la Resolución del Parlamento Europeo del 10 de septiembre del 2015, sobre emprendimiento social e innovación social en la lucha contra el desempleo (2014/2236(INI)) P8_TA (2015)0320. 
en todo momento, de modo que hace propios de esta los datos estadísticos, las formas jurídicas y los principios propios de la primera. ${ }^{22}$

Llama la atención la utilización de la expresión economía social y solidaria por el Parlamento, sin justificar y al margen del sentido con el que las legislaciones europeas han utilizado esta expresión (como se explica continuación). No obstante, y aunque nuestro estudio se ha limitado al contexto europeo, no podemos dejar de señalar que, en el 2010, el Centro Internacional de Formación de la Organización Internacional del Trabajo (CIF-OIT) elaboró el documento "Economía social y solidaria: construyendo un entendimiento común"; en el 2012 se había aprobado la Ley de la Economía Social y Solidaria de México, y en el 2013 se constituyó en Ginebra el Grupo de Trabajo Interinstitucional de las Naciones Unidas sobre Economía Social y Solidaria, también conocido por su abreviatura TFSSE (Task Force on Social and Solidarity Economy), con el objetivo de aumentar la visibilidad de los debates sobre economía social y solidaria, principalmente en la sede de las Naciones Unidas. La expresión "economía social y solidaria" ganaba con esto reconocimiento al más alto nivel público y no podían desconocerla los parlamentarios europeos. ${ }^{23}$ Para el grupo de trabajo TFSSE, ${ }^{24}$ la economía social y solidaria abarca organizaciones y empresas que: 1. Tienen objetivos económicos y sociales explícitos (y a menudo ambientales); 2. Comprenden diversos grados y formas de relaciones cooperativas, asociativas y de solidaridad entre trabajadores, productores y consumidores; 3. Practican la democracia y la autogestión en el lugar de trabajo. La economía social y solidaria comprende formas tradicionales de cooperativas y asociaciones mutuas, así como grupos de

22 Así, comienza por señalar que las empresas de la economía social y solidaria, las cuales no necesariamente tienen que ser organizaciones sin ánimo de lucro, son empresas cuyo objetivo es la realización de su finalidad social, como, por ejemplo, crear empleo para colectivos vulnerables, prestar servicios a sus miembros o, más en general, causar un impacto social y medioambiental positivo; asimismo, que reinvierten sus beneficios, principalmente, con el fin de alcanzar esos objetivos. Destaca también que las empresas de la economía social y solidaria se caracterizan por su compromiso con la defensa de los valores que enumera y son los conocidos como "Principios de la economía social", aprobados por CEP-CMAF.

23 El Comité Económico y Social Europeo, el 22 de febrero del 2012, aprobó un Dictamen titulado "La economía social en América Latina" (REX/325), en el cual manifiesta que a los efectos de dicho documento es más adecuado utilizar el término de economía social y solidaria para referirse al concepto en dicha región.

24 Este grupo de trabajo, en una declaración publicada en julio del 2016 bajo el título "Aplicar la Agenda 2030 a través de la economía social y solidaria", reconoce que la economía social y solidaria coexiste con otras denominaciones de conceptos similares y relacionados como la "economía social solidaria", la "economía social", la "economía solidaria", las "empresas sociales", el "tercer sector" o el "cuarto sector", entre otros, lo que ofrece oportunidades para la cooperación y la ampliación de los efectos de la Ess y las actividades del propio grupo. Disponible en: http://unsse.org/wp-content/uploads/2014/08/ES_Final_Position_Paper_SSE_SDGs_FAO_ Geneva_es.pdf 
autoayuda, grupos comunitarios de silvicultura, organizaciones de previsión social o servicios de proximidad, organizaciones de comercio justo, asociaciones de trabajadores del sector informal, empresas sociales, monedas comunitarias y modelos de financiación alternativos. ${ }^{25}$ La economía social y solidaria agrega a la economía social, como vemos, otras organizaciones con o sin personalidad jurídica y prácticas. ${ }^{26}$

\section{La regulación legal de la economía social en Europa. De la Ley española del 2011 a la Ley griega del 2016}

La economía social, entendida como un conjunto de entidades que comparten los fines y los principios que hoy identificamos bajo esa denominación, comienza a tener presencia en Europa entre los siglos XVIII y XIX como manifestaciones del asociacionismo popular, con el fin de hacer frente a las necesidades propias o de las clases más desprotegidas de la sociedad ante las nuevas condiciones de vida generadas por el capitalismo industrial. Muchas de esas manifestaciones conseguirán ser reconocidas legalmente y se les atribuirá personalidad jurídica como cooperativas, sociedades de socorros mutuos, asociaciones o sindicatos, a lo largo de los siglos XIX y XX. ${ }^{27}$

Sin embargo, si nos referimos a "economía social" como denominación comprensiva de una categoría de empresas, su presencia en las leyes europeas tiene lugar, principalmente, a partir de la Resolución del Parlamento Europeo del 2009, la cual anima a los Estados miembros a reconocer y regular la economía social para darle visibilidad y apoyo. Con anterioridad encontramos normas de organización y fomento,

25 Concepto formulado por Peter Utting, exdirector adjunto de United Nations Research Institute for Social Development (UNRISD), y recogido en la página web del grupo de trabajo TFSSE (véase https://unsse.org/).

26 Según Pablo Guerra (2012), la economía social y solidaria es un conjunto de experiencias económicas, fundadas en valores solidarios, que ha dado lugar en los últimos años al surgimiento de nuevos actores (bancos éticos, organizaciones de comercio justo, empresas autogestionarias, empresas recuperadas, redes de productores orgánicos o productores artesanales, etc.), los cuales, sumados a los actores de mayor tradición (cooperativas, mutuales, asociaciones) caracterizan un sector específico de la economía, a la par que un movimiento social de considerable dinamismo. Pérez y Etxezarreta (2015) conciben la economía solidaria como una superación de la economía social, ya que entienden que esta (la cual identifican con las cooperativas, las mutuas y las asociaciones exclusivamente) en su búsqueda del éxito en los mercados ha acabado por trivializar en muchos casos la propia esencia y los valores de sus empresas y organizaciones, mientras que otras han sido instrumentalizadas por el poder público.

27 Véase Fajardo (2012) para una mayor amplitud sobre los orígenes de estas entidades en Europa y sus relaciones entre ellas. 
así como normas administrativas de reconocimiento de competencias a determinados organismos públicos para llevar a cabo el registro, el fomento y el control de las entidades calificadas como de "economía social". Este es el caso en países como Francia, Bélgica o España. ${ }^{28}$

Una regulación marco de la economía social no tiene lugar en Europa hasta la Ley española de Economía Social en el 2011. ${ }^{29} \mathrm{~A}$ partir de este momento, se aprobaron otras leyes de economía social en Portugal ${ }^{30}$ y Rumania, ${ }^{31}$ y leyes denominadas de "economía social y solidaria" en Francia ${ }^{32}$ y Grecia $^{33}$.

Nuestro objetivo en este punto es analizar algunos aspectos del régimen jurídico de la economía social en estas leyes, así como su justificación, la definición empleada de la economía social, la identificación de las empresas que integran la economía social y la acreditación de su condición. Hemos optado por recoger las leyes de ámbito estatal y descartar las de ámbito regional, sin perjuicio de destacar su relevancia para el desarrollo de sus respectivos territorios, como, por ejemplo, el Decreto sobre Economía Social de Flandes del 17 de febrero del 2012, la Orden del 26 de abril del 2012 sobre economía social en la región de Bruselas, o la Ley de Economía Social de la región española de Galicia del 4 de mayo del 2016. ${ }^{34}$

\section{Justificación de la ley}

Las leyes aprobadas estos años sobre economía social han tenido por objetivo central visibilizar la economía social y establecer medidas para su fomento.

En cuanto a su contenido, todas ellas definen la economía social en referencia a sus fines y características, y regulan, entre otros temas, el reconocimiento formal

28 En este sentido, pueden citarse, en Francia, el Decreto n. ${ }^{\circ} 1125$ del 15 de diciembre de 1981, por el cual se crea la Delegación Interministerial de la Economía social; la Ley 657 del 20 de julio de 1983, relativa al desarrollo de ciertas actividades de economía social, o la Ley 703 del 12 de julio de 1985, que completa la anterior. En Bélgica, el Decreto del 20 de noviembre del 2008 aprueba la reglamentación sobre la economía social en la Región de Valonia, y en España, la Ley $31 / 1990$ del 27 de diciembre crea el Instituto Nacional de Fomento de la Economía Social, y la Ley $27 / 1999$ del 16 de julio crea y regula el Consejo para el Fomento de la Economía Social.

29 Ley n. ${ }^{\circ} 5$ de Economía Social del 29 de marzo del 2011.

30 Ley n. ${ }^{\circ} 30$ de Bases de la Economía Social del 8 de mayo del 2013.

31 Ley $n .{ }^{\circ} 219$ de Economía Social del 23 de julio del 2015.

32 Ley n. ${ }^{\circ} 856$ de Economía Social y Solidaria, del 31 de julio del 2014.

33 Ley n. ${ }^{\circ} 4430$ de Economía Social y Solidaria, y desarrollo de sus entidades, del 31 de octubre del 2016.

34 Yvon Poirier (2016) hace referencia a otras leyes y reglamentos sobre economía social aprobados en regiones o municipios italianos (Trento, Venecia, Roma, Lazio, Liguria, Marche, Emilia Romagna, Val Venosta y Fruili Venecia Guilia). 
de las entidades y las empresas de la economía social; su participación institucional en órganos de decisión público-privados; la determinación del órgano administrativo competente en la materia; y algunas medidas de promoción y fomento en favor de las entidades de economía social y sus organizaciones representativas.

\section{Definición de economía social (y solidaria). Fines y principios}

Las leyes de economía social coinciden al definir la economía social como actividades económicas desarrolladas por empresas que comparten fines y ciertas características. Se emplea el término "actividad" de acuerdo con la definición de la SEE, pero no se trata de actividades económicas concretas que pudiéramos identificar como propias de la economía social, sino más bien de formas de organizar y desarrollar actividades económicas. Por tanto, la referencia a las actividades se complementa con alusiones a la finalidad perseguida con estas y a las características de su organización y desarrollo, también identificadas como principios de la economía social.

Así, en la ley española el fin que persigue esa actividad o es bien el interés colectivo de sus integrantes, el interés general económico o social, o bien ambos (art. 2). En la ley portuguesa el fin que se persigue es el interés general de la sociedad, ${ }^{35}$ directamente o a través de la persecución de los intereses de sus miembros usuarios y beneficiarios, en cuanto sean socialmente relevantes (art. 2). En la ley rumana se alude al interés público, al interés de la comunidad y a los intereses particulares no patrimoniales (art. 2); más en particular, señala que la economía social tiene por objeto fortalecer la cohesión social y económica, el empleo y el desarrollo de servicios sociales, y lo persigue al realizar actividades de interés general tales como son (a) proveer de bienes, servicios o trabajo a la comunidad, y contribuir así al bienestar de la comunidad o de sus miembros; o (b) promover actividades que puedan generar trabajo a personas pertenecientes a grupos vulnerables y desarrollar programas de formación profesional y servicios sociales que mejoren la empleabilidad de las personas que pertenecen a dichos grupos (art. 4).

Encuanto a los principios conformea los cuales sellevan a cabo esas actividades económicas, son similares a los aprobados por las organizaciones representativas de la economía social en Europa y que, como recordamos, son: (a) primacía de la persona y del objetivo social sobre el capital; (b) adhesión voluntaria y abierta; (c)

35 Más ampliamente Namorado (2017). 
control democrático ejercido por sus miembros; ${ }^{36}$ (d) conjunción de los intereses de los miembros usuarios o del interés general; (e) defensa y aplicación de los principios de solidaridad y responsabilidad; ${ }^{37}$ (f) autonomía de gestión e independencia con respecto a los poderes públicos; ${ }^{38}$ y $(\mathrm{g})$ utilización de la mayoría de los excedentes para la consecución de objetivos a favor del desarrollo sostenible, los servicios de interés para los miembros y el interés general. ${ }^{39}$

En el caso de la ley griega, se define la economía social y solidaria como un conjunto de actividades económicas que se basan en una organización alternativa de las relaciones de producción, distribución, consumo y reinversión, basada en los principios de democracia, de igualdad, de solidaridad y cooperación y respeto al medio ambiente y al ser humano (art. 2.1). En esta definición merece destacarse la referencia al carácter "alternativo" del modelo frente a otros modelos (como el público y el capitalista), y el respeto al medio ambiente, que si bien no está excluido de los principios de la economía social, no se refleja de forma tan explícita. ${ }^{40}$

La ley francesa, por su parte, define la economía social y solidaria como "un modo de emprender y de desarrollo económico" al que se adhieren personas jurídicas de derecho privado que cumplen ciertas condiciones relacionadas con sus fines y características. En cuanto a los fines, no se exige perseguir fines de interés general, sino simplemente que el fin no sea solo la distribución de los beneficios. En cuanto a las demás condiciones exigidas, se relacionan con la gobernanza democrática ${ }^{41}$

36 En el caso de la ley española, en lugar de control se habla de gestión transparente, democrática y participativa (art. 4).

37 Esta referencia a la solidaridad y a la responsabilidad se amplía en las leyes española y portuguesa a otros valores y objetivos como, por ejemplo, el compromiso con el desarrollo local, la igualdad de oportunidades entre géneros, la cohesión social, la inserción de personas en riesgo de exclusión social, la generación de empleo estable y de calidad, la conciliación de la vida familiar y laboral, la sostenibilidad o la justicia.

38 Para la ley portuguesa no solo es importante la independencia con respecto a las autoridades públicas, sino también de cualquier otra entidad exterior a la economía social (art. 5).

39 La ley española, además, hace alusión al criterio de distribución de esos excedentes, que deberá ser en función de la participación de los miembros en la actividad. La ley portuguesa, por su parte, advierte la importancia de respetar la especificidad de la distribución de los excedentes propia de la naturaleza de cada entidad, al recordar el carácter irrepartible de los beneficios en buena parte de estas entidades.

40 Puede decirse que, implícitamente, el respeto al medio ambiente puede integrarse tanto en los fines de interés general como en los objetivos del desarrollo sostenible.

41 La gobernanza democrática deberá estar definida y organizada en los estatutos sociales, que preverán la información y la participación no solo vinculada a la aportación de capital o contribución financiera de los asociados, trabajadores y partes interesadas en los objetivos de la empresa (art. $\left.1.12^{\circ}\right)$. 
y la gestión de los beneficios, ${ }^{42}$ condiciones que están en consonancia con algunos principios vistos de la economía social.

\section{Identificación de las llamadas "entidades de la economía social"}

Después de definir la economía social (y en su caso, la economía social y solidaria) las leyes suelen identificar algunos tipos de entidades como representativos de dicha categoría (" $\mathrm{A}$ "), y suelen establecer criterios que permitan identificar nuevas entidades de la economía social ("B").

Así, las instituciones europeas coinciden en identificar como entidades de la economía social las formas clásicas de cooperativa, asociación, mutualidad y fundación y, más recientemente, de empresa social.

Las leyes española, portuguesa y francesa coinciden en identificar como entidades de la economía social las anteriores formas clásicas, ${ }^{43}$ a las que se añaden otras entidades específicas de sus ordenamientos jurídicos. ${ }^{44}$

La ley rumana opta por la denominación de "empresa social" para describir a aquellas entidades de derecho privado que cumplan con los principios propios de la economía social (art. 5), sin hacer referencia a formas jurídicas concretas. ${ }^{45}$ Podría

42 Los beneficios se consagrarán, en su mayoría, al mantenimiento o desarrollo de la actividad de la empresa; las reservas constituidas como irrepartibles podrán, en parte, destinarse a capital, con el fin de elevar el valor de las partes sociales o proceder a distribuir partes sociales gratuitas. En caso de liquidación de la empresa, su haber líquido se destinará conforme indiquen las disposiciones especiales que regulan dicha entidad y en su defecto se destinarán a otra empresa de la economía social y solidaria.

43 La ley española puntualiza que solo las asociaciones y las fundaciones que desarrollen actividades económicas integran la economía social (art. 5), lo que tal vez es redundante, ya que, como vimos, el propio concepto de economía social implica el desarrollo de una actividad económica. La ley portuguesa solo reconoce, en cambio, como economía social a determinadas asociaciones mutualistas y otras asociaciones que con fines altruistas actúen en el ámbito cultural, recreativo, deportivo o en el desarrollo local (art. 4).

44 Así, la ley española incluye también como entidades de la economía social a las sociedades laborales, las sociedades agrarias de transformación y las cofradías de pescadores, todas ellas muy próximas a las cooperativas de trabajadores, de agricultores y de pesca. Por otra parte, también incluye otras entidades que podrían considerarse "empresas sociales", como son las empresas de inserción y los centros especiales de empleo en la ley española, o las misericordias y las instituciones particulares de solidaridad social en la ley portuguesa. Por último, la ley portuguesa también acoge como entidades de la economía social aquellas comprendidas en los subsectores comunitario y autogestionario integrados en el sector cooperativo y social al que se refiere la Constitución portuguesa.

45 No obstante, cabe decir que una de las formas jurídicas reconocidas como empresa social en Rumania es la empresa de inserción social, la cual se regula más adelante en la propia ley (arts. 11 y 12), y también se consideran empresas sociales y, por tanto, perteneciente a la economía social según la doctrina, las sociedades cooperativas (Ley 1/2005); cooperativas 
pensarse que la ley rumana solo regula la empresa social como un modelo particular de empresa y no como categoría general equiparable a la economía social, pero la descripción que hace de empresa social no deja lugar a dudas de que existe una equiparación entre empresa social y entidad de economía social. ${ }^{46}$

La ley griega, por último, identifica como entidades de la economía social las empresas sociales cooperativas (reguladas en la Ley 4430/2016, arts. 14-23); las cooperativas sociales de responsabilidad limitada (Ley 2716/1999, art. 12), y las cooperativas de trabajadores (Ley 4430/2016, arts. 24-34), entidades todas ellas que comparten la forma jurídica de cooperativa ${ }^{47}$.

Sin embargo, además de reconocer determinados tipos de entidades formalmente constituidas como pertenecientes a la economía social, las distintas leyes analizadas suelen establecer criterios que permitan identificar nuevas entidades de la economía social.

Las leyes española, portuguesa y rumana adoptan como criterio el cumplimiento de los principios de la economía social, de forma que cualquier entidad de derecho privado y con personalidad jurídica que desarrolle una actividad económica podrá ser calificada como de "economía social" cuando cumpla con los principios que la caracterizan. Se echa de menos que no se haga una expresa referencia a los intereses generales que deben perseguir estas entidades, bien sea directamente o bien mediante la persecución de los intereses de sus miembros, en cuanto sean socialmente relevantes (como de forma acertada lo recoge la ley portuguesa).

La ley griega reconoce como entidades de la economía social y solidaria solo cooperativas y no de todo tipo; también adopta un criterio que permita ampliar este elenco, pero restringe el mismo a su forma jurídica, y al cumplimiento de ciertas condiciones. Por una parte, señala que cualquier entidad con personalidad jurídica

de crédito (Orden 99/2006); asociaciones y fundaciones (Orden 26/2000); viviendas de ayuda mutua (Leyes 122/1996 y 540/2001); sociedades agrarias (Ley 36/1991); y sus asociaciones y federaciones (Rusandu, 2016).

46 En efecto, porque además de cumplir con los principios de la economía social reconocidos por las instituciones europeas, las empresas sociales en Rumania son las que tienen por objeto fortalecer la cohesión social y económica, el empleo y el desarrollo de servicios sociales, y que pueden llevar a cabo al realizar actividades de interés general como son: (a) proveer de bienes, servicios o trabajo a la comunidad, de manera que contribuyan al bienestar de la comunidad o de sus miembros; y (b) promover actividades que puedan generar trabajo a personas pertenecientes a grupos vulnerables, y desarrollar programas de formación profesional y servicios sociales que mejoren la empleabilidad de las personas pertenecientes a dichos grupos (art. 4). Solo las actividades indicadas en el apartado "B" deben ir destinadas a grupos vulnerables o con difícil empleabilidad, que serían las actividades propias de las empresas sociales, tal y como las definen las instituciones europeas.

47 Más ampliamente sobre la identificación de la economía social en la ley griega: Nasiolas (2016) y Fajardo, G y Frantzeskaki, M. (2017). 
que cumpla las condiciones que veremos a continuación podría calificarse como entidad de la economía social y solidaria; no obstante, a continuación limita esta posibilidad, en especial a favor de las cooperativas agrarias (reguladas por Ley 4384/2016), las cooperativas urbanas (Ley 1667/1986), y las sociedades civiles (Código Civil, art. 741). Las condiciones que estas entidades deben cumplir son muy próximas a los principios de la economía social, pero su mayor concreción limita mucho el ámbito de la economía social y solidaria en Grecia. ${ }^{48}$ No solo hay que estar constituido de determinada forma (principalmente cooperativa), sino que el objeto social debe limitarse a la inserción social, prestar servicios sociales o realizar actividades relacionadas con el desarrollo sostenible; la diferencia salarial entre los trabajadores no debe ser superior a tres veces, y los beneficios deben reinvertirse o destinarse en parte a crear puestos de trabajo o mejorar la remuneración de los trabajadores. Cabe decir que la expresión "economía social y solidaria", en la ley griega, no representa una yuxtaposición de los conceptos (social y solidaria), sino más bien una síntesis, pues solo contempla entidades que sean a la vez sociales y solidarias, lo que se identifica con la expresión "economía social solidaria". ${ }^{49}$

La ley francesa también contempla que otras entidades, además de las clásicas, integren la economía social y solidaria. Estas entidades pueden ser sociedades comerciales que, además de los requisitos propios de la economía social y solidaria que se expusieron, cumplan determinadas condiciones. Por tanto, también podrán formar parte de la economía social y solidaria en Francia las sociedades

48 Las condiciones exigidas para adquirir la condición de entidad de la economía social y solidaria en la ley griega son: 1. Que desarrollen actividades de interés común y social (al satisfacer necesidades generales o comunes de sus miembros; y realizar actividades de desarrollo sostenible, servicios sociales o inserción social); 2 . Que proporcionen información y participación a sus miembros conforme al principio de una persona un voto; 3 . Que su estatuto contemple limitaciones a la distribución de resultados (al menos el $5 \%$ se destine al fondo de reserva y el resto a ampliar la actividad productiva y la creación de nuevos puestos de trabajo; no obstante, el $35 \%$ podrá destinarse a los trabajadores de la entidad, salvo que la Asamblea por $2 / 3$ de sus votos decida destinar también dicho importe al punto anterior); 4. Que apliquen un sistema de remuneración según el cual el máximo salario neto no puede superar más de tres veces el mínimo si la Asamblea por 2/3 de sus votos decide otra cosa; 5 . Que tengan por objetivo el fortalecimiento de sus actividades económicas y la maximización del beneficio social y produzcan mediante la cooperación horizontal con otras entidades de la economía social y solidaria; y 6 . Que no estén constituidas ni dirigidas, directa o indirectamente por personas jurídicas de derecho público (art. 3.1).

49 Expresión que utiliza para su identificación Ripess, la Red Intercontinental de Promoción de la Economía Social Solidaria (véase http://www.ripess.org/?lang=es). A fin de profundizar sobre el sentido de la expresión "economía social solidaria", véase Poirier (2014); y sobre su presencia en la legislación griega, véase Fajardo y Frantzeskaki (2017). 
comerciales $^{50}$ cuyo fin, conforme a sus estatutos, no sea solo repartir beneficios, sino también perseguir una utilidad social, y respeten ciertas normas en su gobernanza y en su gestión económica. Se entiende que una empresa persigue una utilidad social si en sus estatutos consta como un objetivo preferente alguno de los tres que señala la ley. ${ }^{51}$ Su gobernanza deberá ser democrática y con este propósito sus estatutos deberán prever que la información y la participación de los asociados, de los trabajadores y de las partes interesadas en los logros de la empresa no se vinculan de forma exclusiva a su aportación a capital o contribución financiera. ${ }^{52}$ Por último, en su gestión económica, sus estatutos sociales deberán prever que un $20 \%$ al menos de los beneficios se destinen a la constitución de una reserva estatutaria obligatoria denominada "fondo de desarrollo", y otro 50\% al menos a reservas obligatorias; ${ }^{53}$ o que no pueda amortizarse su capital social y solo pueda reducirse por pérdidas, salvo que la reducción asegure la continuidad de la actividad económica de la entidad ${ }^{54}$ (art. 1 ॥). También deberíamos recordar que en caso

50 Según el Código de Comercio francés son sociedades comerciales la sociedad por acciones, la sociedad de responsabilidad limitada, la sociedad comanditaria y la sociedad en nombre colectivo, y todas sus variantes.

51 Así, los estatutos deberán recoger en su objeto social uno al menos de los siguientes objetivos: 1. Aportar a través de su actividad apoyo a personas en situación de fragilidad sea por su situación económica o social, sea por su situación personal y, particularmente, por su estado de salud o sus necesidades en materia de acompañamiento social o medio-social. Estas personas pueden ser los trabajadores, usuarios, clientes, miembros o beneficiarios de esta empresa; 2. Contribuir a la lucha contra las exclusiones y las desigualdades sanitarias, sociales, económicas y culturales; a la educación de la ciudadanía, principalmente por la educación popular; a la preservación y al desarrollo de las relaciones sociales o al mantenimiento o reforzamiento de la cohesión territorial; o 3. Contribuyan al desarrollo sostenible en sus dimensiones económicas, sociales, medioambientales y participativa, a la transición energética o a la solidaridad internacional, siempre que su actividad esté vinculada a uno de los objetivos mencionados en los anteriores puntos 1 y 2 .

52 El Decreto n. ${ }^{\circ}$ 2015-858 del 13 de julio relativo al estatuto de las sociedades comerciales que tengan la cualidad de empresas de la economía social y solidaria complementa esta norma al señalar cómo los estatutos de las sociedades que hacen pública su condición de empresas de la economía social y solidaria deberán contener las estipulaciones relativas a la composición, el funcionamiento y las facultades de los órganos de la empresa, a fin de garantizar su gobernanza democrática y, en particular, la información y la participación de sus socios (que no se vincula exclusivamente a su aportación a capital o contribución financiera), empleados y partes interesadas a los logros de la empresa.

53 El Decreto n. ${ }^{\circ}$ 2015-858 al que hemos hecho referencia en el apartado anterior también señala que estas sociedades deberán reflejar en sus estatutos sociales el destino mayoritario de los beneficios al mantenimiento y desarrollo de la actividad de la sociedad, y el carácter irrepartible y no distribuible de las reservas obligatorias constituidas.

54 Esta norma impide el reembolso del capital, con lo cual limita la posibilidad de inversiones temporales (acciones rescatables) y de ciertos inversores, como, por ejemplo, las sociedades de capital riesgo cuyo objeto social principal consiste en la toma de participaciones temporales en el capital de empresas no financieras. El Decreto n. ${ }^{\circ} \mathbf{2 0 1 5 - 7 6 0 ~ d e l ~} 24$ de junio del 2015 
de liquidación de las entidades de la economía social y solidaria, su haber líquido se destinará a otra empresa de la economía social y solidaria (art. 1 I). En este caso, el ámbito de la economía social y solidaria es más amplio, pues yuxtapone a las formas clásicas de la economía social (cooperativas, mutuas, asociaciones y fundaciones) las que denomina "empresas solidarias", ${ }^{55}$ un abanico de sociedades mercantiles caracterizadas por tener un objeto de utilidad social, una gobernanza democrática y participativa y un limitado ánimo lucrativo. ${ }^{56}$ Puede decirse que su ánimo de lucro se ve limitado porque solo pueden distribuir el 30\% de sus beneficios, y el patrimonio que quede al momento de su liquidación, una vez satisfechas todas las deudas, tampoco puede distribuirse entre los socios, lo que reduce el interés en comerciar con acciones o participaciones sociales. ${ }^{57}$

\section{Acreditación de la condición de entidad de la economía social}

Las leyes que analizamos no solo describen los requisitos que deben cumplir las entidades de la economía social (y solidaria), sino que establecen mecanismos para su reconocimiento formal a fin de contribuir a su visibilidad y facilitar su promoción.

establece los supuestos en que excepcionalmente podrá reducirse el capital social por causas ajenas a las pérdidas.

55 El Código de Trabajo francés (art. L 3332-17-1) regula desde su modificación por la Ley 776 del 4 de agosto del 2008, "empresas solidarias" como aquellas que al no estar sus títulos de capital admitidos a cotización oficial en mercado reglado, emplean trabajadores con contratos de trabajo asistido o en situación de inserción profesional; cumplen ciertas normas sobre remuneración de sus dirigentes y trabajadores y son autorizadas por la administración. Se asimilan a estas las empresas controladas en un $35 \%$ por empresas solidarias, así como las entidades de crédito y financieras en las que el $80 \%$ de sus préstamos e inversiones se efectúen en favor de empresas solidarias. La Ley de economía social y solidaria ha modificado este precepto en su artículo 11 al sustituir la expresión "empresa solidaria" por la de "empresa solidaria de utilidad social", e incorporar importantes modificaciones: declara que la empresa solidaria de utilidad social (ESUS) pertenece a la economía social y solidaria; que su objetivo social busca una utilidad social y tiene un impacto significativo sobre la cuenta de resultados o la rentabilidad financiera de la empresa, o la política de remuneración de esta cumple ciertos requisitos que limitan la brecha salarial. A continuación, señala algunos ejemplos de Esus: las empresas de inserción, empresas de trabajo temporal de inserción, asociaciones intermediarias, talleres de inserción, servicios de ayuda a la infancia, centros de alojamiento e inserción social, empresas adaptadas, centros de distribución del trabajo a domicilio, establecimientos y servicios de ayuda al trabajo, asociaciones y fundaciones reconocidas de utilidad pública, entidades de acción social y establecimientos y servicios de acompañamiento y acogida de niños y de adultos discapacitados, entre otras.

56 Sobre el nuevo ámbito de la economía social y solidaria en Francia, Véase Hiez y Lavillunière (2013).

57 A fin de profundizar sobre esta Ley, véase Duverger (2016), así como Defourny y Nyssens (2017). 
Los criterios utilizados para dicha acreditación también son diversos en las leyes analizadas.

La ley española parece presumir que las diversas entidades que enumera cumplen los principios requeridos y, por tanto, forman parte sin más de la economía social, mientras que las demás entidades tendrán que demostrar el cumplimiento de dichos principios. Sin embargo, por otra parte, la misma ley ordena al Ministerio de Trabajo e Inmigración que elabore, publique y mantenga actualizado un catálogo de los diferentes tipos de entidades integrantes de la economía social, de acuerdo con los principios que las caracterizan, ${ }^{58}$ lo que hace presumir que el catálogo podrá incorporar nuevos tipos de entidades, pero también podrá eliminar aquellos que ya no cumplan con los principios. ${ }^{59}$ El catálogo no está constituido ni regulado todavía, pero no parece que vaya a tratarse de un registro o catálogo de entidades, ${ }^{60}$ sino de un catálogo de "tipos de entidades", de categorías de entidades. Con la aprobación de la "Estrategia Española de la Economía Social 2017-2020" se establecen como medidas a adoptar la elaboración del catálogo de las entidades de la economía social, del que dice que contendrá "los diferentes tipos de entidades integrantes de la economía social" (n. ${ }^{\circ}$ 18), y la creación del sello de entidad de la economía social, el cual permitirá "identificar a todas y cada una de las empresas y organizaciones que conforman el sector" (n. ${ }^{\circ}$ 19). La acreditación de las entidades de la economía social parece que va a tener lugar por dos vías: por el catálogo de tipos de entidades y por la atribución del sello como entidad de la economía social. La previsible regulación del catálogo resolverá la cuestión sobre si todas las entidades citadas en la ley se integrarán en el catálogo o podrá limitarse este acceso a aquellas que cumplan los principios orientadores.

La ley portuguesa contempla la creación, la publicación y la actualización de una base de datos permanente de las entidades de la economía social que será competencia del Gobierno (art. 6); competencia que ha sido recientemente transferida a la Cooperativa António Sérgio para la Economía social (Decreto-Ley núm. 39/2017, del 4 de abril). Esta base de datos no ha sido creada todavía, pero en el 2015 el Consejo

58 Según el art. 6 de la ley española titulado "Catálogo de entidades de economía social", "el Ministerio de Trabajo e Inmigración, previo informe del Consejo para el Fomento de la Economía Social, y en coordinación con las Comunidades Autónomas, elaborará y mantendrá actualizado un catálogo de los diferentes tipos de entidades integrantes de la economía social, teniendo en cuenta los principios establecidos en la presente ley y de forma coordinada con los catálogos existentes en el ámbito autonómico. Los catálogos de entidades de economía social deberán ser públicos. La publicidad se hará efectiva por medios electrónicos".

59 Tal como lo sugiere la doctrina. Véase, entre otros, Paniagua (2011) o Paz Canalejo (2012).

60 La ley gallega de economía social sí contempla la creación de un catálogo de entidades de la economía social que se nutrirá y actualizará con la información recibida de los diversos registros en los que se inscriben las diversas entidades de la economía social gallegas (art. 7). 
Nacional de la Economía Social de Portugal creó un grupo de trabajo para la creación de esta base de datos, y de lo publicado hasta el momento se deduce que la base de datos recogerá información sobre todas y cada una de las entidades pertenecientes a la economía social, principalmente, datos identificativos, información estructural y económico-financiera, así como datos sobre empleo y voluntariado, entre otros. ${ }^{61}$

La ley francesa distingue, por una parte, las entidades clásicas de la economía social que podrán hacer pública sin más su condición de tales, mientras que las sociedades comerciales se inscribirán en el Registro de comercio y de sociedades con la mención de calidad de economía social y solidaria (art. 1. III). El funcionario encargado del Registro debería comprobar la legalidad de la inscripción y, por tanto, no inscribir una entidad con la mención de empresa de economía social y solidaria si no constan en sus estatutos sociales las menciones previstas en la ley: ${ }^{62}$ un objeto social prioritario de utilidad social, una gobernanza democrática y participativa y una gestión económica que priorice la reinversión en el objeto social frente al lucro.

La ley rumana contempla una certificación como empresa social y un registro único que se ocupa del inventario de las empresas sociales. La certificación como empresa social puede solicitarla cualquier persona jurídica cuya actividad se base en los principios de la economía social y persiga los objetivos que marca la ley en su artículo 4 que se expusieron (art. 9.1). La certificación como empresa social la concede la agencia de empleo local, por medio de su división de economía social. ${ }^{63}$ Esa certificación se concede por un periodo de cinco años, con posibilidad de renovación si se prueba que se siguen respetando las condiciones requeridas para su otorgamiento. Cualquier cambio en las condiciones que tuvieron que acreditarse para obtener el certificado deberá comunicarse a la agencia de empleo en el plazo de 15 días (art. 10). El registro único para el inventario de las empresas sociales tiene como objeto garantizar una información precisa y completa con respecto a la situación y la evolución del ámbito de la economía social a nivel nacional. Dicho registro será gestionado por la Agencia Nacional de Empleo y recogerá información sobre todas las empresas de economía social de Rumania. ${ }^{64}$

61 Véase http://www.cases.pt/wp-content/uploads/20150529_Relatorio_GT_BDPEES.pdf

62 La cual vuelve a recoger y desarrollar el Decreto $n .^{\circ} 2015-858$ mencionado.

63 La competencia en materia de economía social es del Ministerio de Empleo, Familia y Protección Social, y en particular de la Dirección de Empleo e Igualdad de Oportunidades. En la Agencia Nacional para el Empleo existe un Departamento para la Economía Social que coordina y controla la actividad de las agencias de empleo en materia de economía social (art. 24).

64 Los datos recogidos harán referencia a la identificación de la entidad, el nombre, la fecha de constitución, el campo de actividad, el volumen de negocios, el valor de sus activos, los beneficios o las pérdidas obtenidos en el último ejercicio fiscal, el número total de empleados, la acreditación de pertenecer a un grupo vulnerable, la descripción del trabajo de los empleados 
La ley griega, por el contrario, ha optado por la creación de un registro general de entidades de la economía social y solidaria. ${ }^{65}$ Este registro se ocupa de comprobar el cumplimiento de los requisitos por parte de estas entidades y de darles la calificación como entidades de la economía social y solidaria (art. 4).

\section{Conclusiones}

El concepto de economía social resurgió en la década de los ochenta del siglo pasado como una reivindicación promovida por las entidades representativas de determinados tipos de empresas (cooperativas, mutuas, asociaciones y fundaciones), diferentes a las convencionales sociedades mercantiles (lucrativas o sociedades de capital), que reclamaban su derecho al desarrollo en igualdad de condiciones frente a otros modelos de empresa, sin tener que renunciar a su identidad.

Sin embargo, esta reivindicación se ha entendido por parte de las instituciones europeas y de los Estados como la necesidad de visibilizar y fomentar la economía social, lo que exige definirla, valorar su relevancia social y aplicar políticas de promoción.

Por otra parte, el Comité Económico y Social Europeo aprobó un dictamen el 1 de octubre del 2009, titulado "Distintos tipos de empresa" (INT/447), en el que abogaba por la salvaguarda y fomento de la diversidad de formas de empresa que existen en la Unión Europea, en razón a que dicha diversidad constituye un valioso patrimonio imprescindible para el logro de los objetivos que se plantea la Unión en materia de crecimiento, empleo, desarrollo sostenible y cohesión social. El dictamen reclama que el marco jurídico europeo se adapte a las características de los diferentes agentes económicos que actúan en el mercado, a fin de que se logre la igualdad de condiciones entre todas las diferentes formas de empresa, en conformidad con las características de cada una de ellas, y reconoce que, en la actualidad, ese marco está destinado - por lo general- a las grandes empresas que cotizan en bolsa, y que su aplicación a todos los tipos de empresas crea obstáculos para las demás empresas. Por tanto, analiza a continuación los principales ámbitos de dicho marco jurídico (derecho de sociedades, derecho contable, derecho de la competencia, derecho fiscal y armonización estadística), y propone medidas eficaces que no dejan de ser recomendaciones y que no han sido atendidas.

pertenecientes a este grupo; el tipo de ayudas que percibe el empleador; las infracciones cometidas por el empleador y las sanciones; la fecha de concesión, la suspensión o la retirada del certificado (art. 26).

65 La gestión de este registro depende del Departamento de Supervisión y Control de las Entidades de Economía Social y Solidaria del Ministerio de Trabajo, Seguridad Social y Solidaridad Social (art. 11). 
También hemos podido ver cómo el concepto de economía social se ha ido adaptando en cada Estado de acuerdo con su marco jurídico y los modelos de empresa más afines a dicho concepto. No obstante, son pocos los Estados que han reconocido legalmente la economía social como una categoría jurídica identificativa de diversos modelos de empresa, si bien dichos modelos (cooperativas, mutuas, asociaciones y fundaciones) están, por lo general, reconocidos y regulados en los diversos Estados de la Unión Europea.

Hemos comprobado también cómo empresas que pueden adoptar formas jurídicas mercantiles se han incorporado pacíficamente en el concepto de economía social, pues se trata de empresas de inserción y empresas de iniciativa social con fines de interés general, comúnmente denominadas "empresas sociales".

Ahora bien, esta incorporación plantea problemas en la medida en que el concepto de empresa social está en fase de consolidación y con tendencia a integrar cualquier iniciativa empresarial que aporte valor social medible. ${ }^{66}$ El concepto que actualmente utilizan las instituciones europeas entiende la empresa social como una empresa cuyo objetivo primordial es conseguir impactos sociales positivos y mensurables, que ofrece bienes o servicios con elevado retorno social o emplea métodos de producción que encarnan su objetivo social. Además de lo difícil que es concretar estos requisitos, no se exige gestión democrática ni ausencia de ánimo lucrativo. En definitiva, la empresa social -que adopta normalmente el estatuto jurídico de las empresas de capital- se considera empresa de economía social, se le atribuyen sus valores y principios y, por tanto, se le hace acreedora de las principales medidas que hasta el momento ha aprobado la Unión Europea en favor de la economía social, lo que no deja de ser una paradoja.

Así, mientras se debate qué es economía social y economía solidaria, o los nuevos conceptos de empresas B, empresas del bien común, empresas colaborativas, tercer sector o cuarto sector, las cooperativas, las mutualidades, las asociaciones y las fundaciones siguen estando discriminadas en el marco jurídico empresarial tanto en la Unión Europea como en los Estados miembros, al ver cómo se reduce y condiciona cada vez más su ámbito de actuación, o cómo se les expulsa del mercado si no abandonan su estatuto jurídico. ${ }^{67}$

66 Como dice el Informe del parlamentario europeo Jiri Mastalka a la Comisión Europea sobre el Estatuto de las empresas sociales y solidarias del 23 de octubre del 2017 (2016/2237 (INL)): existe una tendencia en las legislaciones nacionales a ampliar el ámbito de actividades que pueden desarrollar las empresas sociales, siempre que sean de interés general o utilidad social, y cita como ejemplo la provisión de servicios comunitarios educacionales, culturales, etc.

67 Esta situación de confusión generada por las instituciones europeas ha sido criticada en la doctrina. Véanse, entre otros: Monzón y Chaves (2017); Monzón y Herrero (2012); y Pedreño (2017). En particular, destacamos la posición de Social Economy Europe sobre el proyecto de 


\section{Referencias}

Barea, J. y Monzón, J. L. (2007). Manual para la elaboración de las cuentas satélites de las empresas de la Economía Social: Cooperativas y Mutuas. España: Ed. Ciriec.

Defourny, J., Favreau, L. y Laville, J.-L. (Ed.). (1998). Insertion et nouvelle économie sociale, un bilan international. París.

Defourny, J. (2009). Economia Social. En A. D Cattani, J-L. Laville, L. I. Gaiger y P. Hespanha (Coord:), Dicionário Internacional da Outra Economia (pp. 156-161). San Pablo: Almedina \& CES.

Defourny, J. y Nyssens, M. (2017). Économie sociale et solidaire. Socioéconomie du $3^{\circ}$ secteur. Ouvertures Économiques, De Boeck.

Demoustier, D. (2001). L'économie sociale et solidaire, s'associer pour entreprendre autrement. París: Syros, Aternatives économiques.

Duverger, T. (2016). Les transformations institutionnelles de l'économie sociale e solidaire en France des années 1960 à nos jours. Revue Interventions économiques. Papers in Political Economy, (54), Economie sociale et solidaire: ses écosystèmes.

Espagne, F. (2002). Sur l'économie sociale et solidaire. Recma, (286), 13-22.

Fajardo, G. (2012). Las empresas de economía social en la Ley 5/2011, de 29 de marzo. Rds, (38), 245-280.

Fajardo, G. y Frantzeskaki, M. (2017). La economía social y solidaria en Grecia. Marco jurídico, entidades y principales características. Revesco. Revista de Estudios Cooperativos, (125), 49-88.

Guerra, P. (2012, julio-diciembre). "Las legislaciones sobre economía social y solidaria en América Latina. Entre la autogestión y la visión sectorial". Revista de la Facultad de Derecho. (33), 73-94.

Guridi, L. y Pérez-Mendiguren, J. C. (2014). La dimensión económica del desarrollo humano local: la economía social y solidaria. Hegoa, Bilbao: Universidad del País Vasco.

Informe del Parlamento Europeo "Un estatuto para las empresas sociales y solidarias", manifestada en la Sesión conjunta de las Comisiones de Asuntos Jurídicos (JURI), y de Empleo y Asuntos Sociales (EMPL) del Parlamento Europeo, celebrada el 22 de marzo del 2017, en la que se afirma que esa confusión impide la correcta y completa identificación del conjunto de la economía social y limita el establecimiento de medidas para fomentar su modelo de empresa. 
Hiez, D. y Lavillunière, E. (2013). Vers une théorie de l'économie sociale et solidaire. Bruselas: Ed. Larcier.

Jeantet, T. y Verdier, R. (1982). L'économie sociale. París: Ed. Ciem.

Monzón, J. L y Chaves, R. (2012). La economía social en la Unión Europea. Bruselas: Comité Económico y Social Europeo.

Monzón, J. L. y Chaves, R. (2017). Evolución reciente de la economía social en la Unión Europea. Comité Económico y Social Europeo (CES/CSS/12/2016/23406).

Monzón, J. L y Herrero, M. (2017). Empresas sociales, emprendimiento social y economía social. Revista Española del Tercer Sector, (35), 19-44.

Moreau, J. (1982). Essai sur une politique de l'économie sociale. París: Ed. Ciem.

Namorado, R. (2017, enero). "O que é a economía social?" Economía Social em Textos, (1). Recuperado de http://www.uc.pt/feuc/ceces/est/1

Nasioulas, I. (2016, diciembre 1). The Greek law 4430/2016 on social and solidarity economy breakthroughs and backdrops. The Social Economy Institute, (2).

Neurisse, A. (1983). L'économie sociale, Qué sais-je? París: Ed. Puf.

Paniagua, M. (2011). Las empresas de la economía social. Más allá del comentario a la Ley 5/2011, de economía social. Madrid, Barcelona, Buenos Aires: Marcial Pons.

Paz Canalejo, N. (2012). Comentario sistemático a la Ley 5/2011, de Economía Social. Valencia: Tirant lo Blanch.

Pedreño, J. A. (2017). Reflexiones, sinergias y clarificación sobre nuevos conceptos y modelos: economía social, empresa social, emprendimiento social, economía del bien común, economía solidaria y economía colaborativa. Revista Española del Tercer Sector, (35), 45-72.

Pérez Mendiguren, J. C. y Etxezarreta, E. (2015, abril). Los debates en torno a la economía social y solidaria. Boletín de recursos de información, (42). Recuperado de http:// boletín.ehu.es/ mail/36

Poirier, Y. (2014). Economía social solidaria y sus conceptos cercanos. Recuperado de http://base. socioeco.org/docs/economie_solidaria_y_sus_conceptos_cercanos-poirier-julio-2014.pdf 
Poirier, Y. (2016). Reconocimiento jurídico y político de la economía social solidaria (ESS). Panorama general y elementos de orientación. Recuperado de https://www.economiasolidaria.org/sites/default/files/Yvon-Poirier-reconocimiento-juridico-y-politico-ess_enero-2016-es.pdf

Rusandu, O. (2016). The Romanian social economy law, Fitth European Forum on Social Entrepreneurship, Plovdiv, abril 1 del 2016.

Vienney, C. (1983). Concepts et champs de l'économie sociale. Recma, (9), 50-68. 